\title{
PROGRAMA GRÁFICO DESENVOLVIDO EM PYTHON PARA ANÁLISE E FILTRAGEM AUTOMÁTICA DA VARIABILIDADE DA FREQUÊNCIA CARDÍACA
}

\author{
João Luiz França Silva ${ }^{1}$ \\ Valdir Gil Pillat ${ }^{2}$ \\ Laurita dos Santos ${ }^{3}$
}

\begin{abstract}
Resumo: O TRR-Filter é um programa desenvolvido para filtragem de séries temporais de intervalos RR (duração de um batimento cardíaco completo). Este artigo apresenta o processo de reestruturação do programa TRR-Filter para a linguagem Python com a meta de torna-lo portátil entre sistemas operacionais, além de adicionar outras funcionalidades. O TRR-Filter realiza filtragens automáticas de batimentos cardíacos e plota tacogramas com os dados originais e filtrados que foi feito por Dos Santos et al (2016). O programa foi feito com sucesso e está nas fases finais de testagem.

Palavras-chave: Variabilidade da frequência cardíaca; Filtro adaptativo; Desenvolvimento de interface gráfica para Python; Interface gráfica; Tacograma.
\end{abstract}

\footnotetext{
1 Engenharia/Universidade do Vale do Paraíba, Brasil. E-mail: jluizfs16@gmail.com.

2 Universidade do Vale do Paraíba, Brasil, País. E-mail: valdirgp@univap.br.

3 Universidade do Vale do Paraíba, Brasil, País. E-mail: lauritas9@gmail.com.
} 